\title{
ANÁLISIS Y TRATAMIENTO DE IMÁGENES DEL DEPARTAMENTO MERCEDES (CORRIENTES): ESTUDIO PARTICULAR SOBRE LA EXPANSIÓN DEL ÁREA URBANA DE LAS PRINCIPALES LOCALIDADES DEL DEPARTAMENTO
}

\author{
ANALYSIS AND TREATMENT OF IMAGES OF THE MERCEDES DEPARTMENT (CORRIENTES): PARTICULAR \\ STUDY ON THE EXPANSION OF THE URBAN AREA OF THE MAIN LOCALITIES OF THE DEPARTMENT"
}

\author{
Prof. Fernanda Alarcón \\ Dra. Liliana Ramírez \\ Instituto de Geografía - \\ Facultad de Humanidades - UNNE \\ E-mail: Iramirez@hum.unne.edu.ar
}

\begin{abstract}
RESUMEN
Las imágenes provistas por satélites constituyen en la actualidad, y desde aproximadamente dos décadas, un importante insumo para el desarrollo de estudios de diversos fenómenos que ocurren sobre la superficie terrestre. Particularmente en este trabajo las imágenes satelitales, tratadas a través de procesadores digitales adecuados, se utilizan para analizar los usos del suelo, en especial de tipo urbano, de un departamento del centro sur de la provincia de Corrientes: Mercedes, como así también para observar la evolución de la mancha urbana en las principales localidades del departamento: Mercedes (ciudad cabecera del departamento), Mariano Indalecio Loza y Felipe Yofre (ambas localidades menores situadas a pocos kilómetros de la ciudad principal) en el periodo 1985/1986 - 2008.
\end{abstract}

\section{PALABRAS CLAVES:}

Imágenes satelitales; uso de suelo urbano; expansión de la mancha urbana.

\section{SUMMARY}

The provided images by satellites constitute at present, and from approximately two decades, an important consumption for the development of studies of diverse phenomena that happen on the terrestrial surface. Particularly in this work the satelite images, tried through suitable digital processors, are used to analyze the uses of the ground, especially of urban type, a department of the South center of the province of Currents: Mercedes, like thus also observing the evolution of urban La Mancha in the main localities of the department: Mercedes (city head of the department), Mariano Indalecio Loza and Felipe Yofre (both smaller localities located to few kilometers of the main city) in period 1985/1986 - 2008.

\section{KEY WORDS}

Satelite images; urban ground use; expansion of urban area.

\section{SUMARIO:}

1.- Introducción

2.- La Teledetección y sus aplicaciones: el caso particular de los estudios urbanos 
3.- Área de estudio:

a. Localización del departamento.

b. Descripción de las localidades del departamento.

4.- Materiales y Fuentes de información

5.- Tratamiento de imágenes

a. Corrección y mejora de la visualización de las imágenes

b. Análisis de las imágenes

6.- Descripción de resultados

a. El crecimiento de la ciudad de Mercedes

7.- Consideraciones finales

8.- Bibliografía

\section{INTRODUCCIÓN}

Las imágenes proporcionadas por satélites, hoy disponibles con relativa facilidad, acompañadas por el gran desarrollo y avance en los instrumentos y técnicas de observación remota, como así también por la existencia de adecuados programas de tratamiento digital, permiten que se lleven a cabo diferentes estudios acerca de los fenómenos que acontecen en la superficie terrestre. En este sentido es apropiado citar una frase de Emilio Chuvieco, contenida en su libro "Fundamentos de Teledetección" editado en 1996:

“(...)Con el progresivo avance que han experimentado los instrumentos y técnicas de observación remota durante los últimos años, el estudio de los fenómenos de la superficie terrestre ha podido ser abordado con una profundidad sin precedentes (...)"

En efecto, el desarrollo de los sensores remotos y más precisamente los productos que ellos brindan, nos permiten realizar múltiples estudios que van desde su empleo para elaborar inventarios y evaluación de recursos naturales, hasta realizar análisis agrarios y urbanos, entre otros.

\section{LA TELEDETECCIÓN Y SUS APLICACIONES: EL CASO PARTICULAR DE LOS ESTUDIOS URBANOS}

"La Teledetección desde satélite, es aquella técnica que nos permite obtener información a distancia de los objetos situados sobre la superficie terrestre, cuenta con numerosas aplicaciones, gracias a las ventajas que ofrece frente a otros medios de observación más convencionales..." (Chuvieco, 1996: 37).

En las últimas décadas la Teledetección y los Sistemas de Información Geográfica (SIG) se han convertido en recursos muy útiles para la gestión y ordenamiento de los territorios, además la información proveniente de sensores remotos, 
concretamente las imágenes de satélite, poseen un valor científico potencial para los investigadores de distintas áreas, entre ellos se puede mencionar la utilidad para el estudio de la dinámica urbana.

Si nos dedicamos a exponer brevemente los antecedentes en este tipo de estudios a partir de sensores remotos podríamos remontarnos a la época en que eran indispensables las fotografías áreas. Los estudios realizados a partir de ellas están dirigidos básicamente hacia la morfología y comportamiento urbano o de cobertura del suelo en general. La información proporcionada por las fotografías áreas a pesar de presentar numerosas ventajas como una alta resolución espacial, velocidad en la obtención de información para un área dada, entre otras; también presenta limitaciones como una débil cobertura espacial, el fatigoso tratamiento visual, los errores geométricos introducidos por la perspectiva cónica y el complejo procedimiento de trasladar la información al plano, además de que el trabajo resultaba costoso y a veces se establecía una diferencia temporal importante entre la fecha de adquisición de la fotografía y la publicación del trabajo. Esto alentó a que se buscaran nuevas alternativas. (Zuleima Molina M., Gladys. 2005. Pag: 4)

La utilización de sensores espaciales en aplicaciones terrestres comienza en 1972 con el lanzamiento del primer satélite de la serie ERTS ${ }^{(\underline{1})}$, precursor del satélite Landsat, y específicamente a través del sensor MSS $^{(2)}$ que posee una resolución espacial de 79 × 57 metros y cuatro bandas espectrales. A partir de 1984 se han utilizado los datos provenientes del sensor $\mathrm{TM}^{(3)}$ que posee una resolución espacial de 30 × 30 metros y siete bandas espectrales; desde 1986, los datos provenientes del satélite francés SPOT ${ }^{(4)}$, cuya resolución espacial en modo multiespectral es de $20 \mathrm{x}$ 20 metros y en modo pancromático de 10 x 10 metros y, recientemente (años 1999-2000), los datos del sensor ETM $^{(5)}$ de la serie Landsat que incorpora una banda pancromática de $15 \times 15$ metros y los datos del satélite IKONOS $^{(6)}$ que posee 4 bandas en modo multiespectral con resolución de $4 \times 4$ metros, y una banda pancromática de 1 x 1 metro de resolución. Los últimos satélites de alta resolución espacial son el Quinck Bird y también el GeoEye, ambos con detalle de información submétrica en el canal pancromático.

A partir de 1999, con la liberación tecnológica promovida en 1994 por el gobierno de los Estados Unidos de América, comienzan a ser utilizadas, en el campo de las aplicaciones urbanas imágenes satelitales provenientes de numerosos satélites como los de la serie Landsat, SPOT, etc.

Según Zuleima Molina (2005: 5) son varias las razones que pueden justificar el empleo de imágenes satelitales en los estudios urbanos:

- Posibilidad de actualizar información en cortos períodos de tiempo.

- Al aparecer en un formato digital el tratamiento que se realice es más ágil y rápido.

- La información es más barata y asequible, además hoy podemos obtenerlas a través de páginas web de manera gratuita.

- Al ser automatizados los procesos, hay más objetividad en los tratamientos.

- Da la posibilidad de comparar con otros ámbitos, pues el mismo sensor proporciona información similar sobre otras ciudades.

- Permite crear nueva información dado su carácter multiespectral, lo cual no es posible en otros documentos (fotografías aéreas o mapas).

Debido a estos beneficios el análisis de las características urbanas, mediante el empleo de imágenes satelitales, se 
vuelve más fácil ya que se logra tener una visión general de las mismas y a diferentes escalas. El análisis además puede ser de carácter multitemporal, es decir estudiar el fenómeno en distintos momentos y establecer comparaciones ya que los satélites poseen cobertura global y periódica y una visión amplia que permite detectar grandes espacios.

Otra ventaja es la de contar con la información, es de decir con la imagen en formato digital, lo cual facilita el trabajo, ya que el análisis digital de la imagen agiliza el proceso de interpretación, con una alta precisión.

(1) ERTS: Earth Resources Technology Satellite - Satélite para la Tecnología de los Recursos de la Tierra

(2) MSS: Multi Spectral Scanner

(3) TM: Tematic Mapper

(4) SPOT: Sistema Probatorio de Observación de la Tierra o Satélite Para la Observación de la Tierra

(5) ETM: Edvance Tematic Mapper

(6) IKONOS. En griego "imagen"

\section{MÉTODO DE TRABAJO}

\section{3. ÁREA DE ESTUDIO}

\section{a. Localización del Departamento:}

Como ya se expusiera en la introducción, el área de estudio de este trabajo es el Departamento de Mercedes, en la provincia de Corrientes. El mismo se encuentra situado en el centro sur de la provincia homónima. Posee una superficie de $9.920 \mathrm{Km}^{2}$, que, en términos porcentuales, representa alrededor de un $11 \%$ de la superficie provincial, esto determina que sea uno de las jurisdicciones más extensas de la provincia junto con Ituzaingó, Curuzú Cuatiá y SantoTomé.

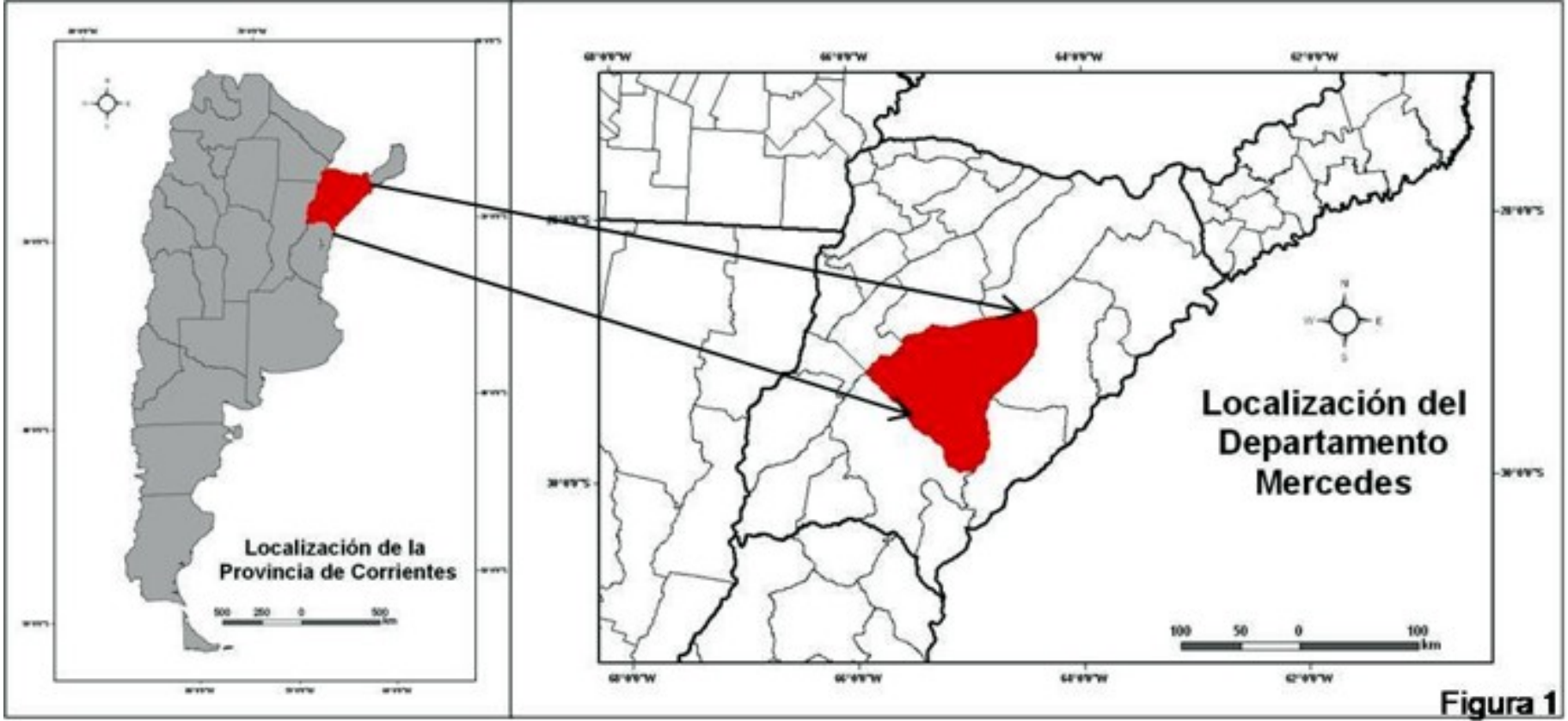

En cuanto a los límites interdepartamentales, podemos citar que al este el río Miriñay, separa a Mercedes de Paso de los Libres y San Martín; por el sur el límite se encuentra dado por el arroyo Villanueva, afluente del río Corriente, el Aguay y el Yuquerí, afluentes del Miriñay, lo separan de Curuzú Cuatiá. Por otra parte, el río Corriente y los Esteros del 
Ibera constituyen el límite norte y oeste entre Mercedes y los departamentos San Roque, Concepción e Ituzaingó.

\section{b. Descripción de las localidades en estudio:}

La ciudad de Mercedes, cabecera del departamento de igual nombre, se encuentra ubicada en el centro oeste del mismo, dista a $270 \mathrm{Km}$. de la ciudad de Corrientes, capital de la provincia. El rjifo original del pueblo se desarró en tierras donadas por Don José María Gómez a principios de 1800, la ciudad debe su nombre a la Virgen Nuestra Señora de las Mercedes. En 1835 la localidad toma el nombre definitivo de Mercedes, en 1864 asciende a categoría de villa y en 1888 a la de ciudad. Se halla bordeada al norte por puntas del arroyo Paiubre, al sur por los arroyos Zanja y Las Flores; y al este y noreste por el arroyo Las Garzas. Por decreto Ley № 66 del año 2000 se fija la jurisdicción territorial del Municipio de Mercedes, el cual es una Comuna de $1^{\mathrm{a}}$ categoría.

La localidad de Mariano Indalecio Loza, conocida también como Estación Solari debido a la influencia del ferrocarril en su nacimiento y consolidación, se ubica al suroeste de la ciudad de Mercedes, aproximadamente a $30 \mathrm{Km}$, sobre la ruta provincial 119, muy próxima al límite con el departamento de Curuzú Cuatiá. Esta localidad en la actualidad posee un poco más de 2000 habitantes.

La localidad de Felipe Yofre se ubica a unos $28 \mathrm{Km}$ de la ciudad de Mercedes, hacia el noroeste, situada sobre la ruta provincial 123. Posee una población cercana a los 2000 habitantes.

\section{4.- MATERIALES Y FUENTES DE INFORMACIÓN}

Para realizar el estudio del uso de suelo urbano, y particularmente para analizar la evolución del fenómeno en el tiempo, es importante contar con los materiales o fuentes de información primaria, constituida en este caso por las imágenes de satélite proporcionadas por el satélite Landsat, obtenidas gratuitamente desde el sitio Web del Instituto Nacional de Pesquisas Espaciales de Brasil ${ }^{(7)}$. La elección de estas imágenes se hace en base a los requerimientos del estudio, es decir a los objetivos y al grado de precisión que se pretende alcanzar; así para apreciar la expansión de la mancha urbana que ocupan las localidades señaladas, se obtuvieron las imágenes detalladas en el siguiente cuadro:

\begin{tabular}{|c|c|c|}
\hline Satélite y Sensor & Área cubierta & Fecha \\
\hline Landsat - TM & $\begin{array}{l}\text { Porción Este (entre los } 27^{\circ} \text { y los } 29^{\circ} \text { de Lat. Sur y los } \\
56^{\circ} \text { y } 57^{\circ} \text { de Long. Oeste) }\end{array}$ & $6 / 04 / 2008$ \\
\hline Landsat - TM & $\begin{array}{l}\text { Porción Oeste (entre los } 27^{\circ} \text { y los } 29^{\circ} \text { de Lat. Sur y los } \\
58^{\circ} \text { y } 59^{\circ} \text { de Long. Oeste) }\end{array}$ & $24 / 01 / 2008$ \\
\hline Landsat - TM & $\begin{array}{l}\text { Porción Sur (entre los } 29^{\circ} \text { y los } 31^{\circ} \text { de Lat. Sur y los } \\
56^{\circ} \text { y } 58^{\circ} \text { de Long. Oeste) }\end{array}$ & $21 / 03 / 2008$ \\
\hline Landsat - TM & $\begin{array}{l}\text { Porción Este (entre los } 27^{\circ} \text { y los } 29^{\circ} \text { de Lat. Sur y los } \\
56^{\circ} \text { y } 57^{\circ} \text { de Long. Oeste. }\end{array}$ & $17 / 11 / 1985$ \\
\hline Landsat - TM & $\begin{array}{l}\text { Porción Oeste (entre los } 27^{\circ} \text { y los } 29^{\circ} \text { de Lat. Sur y los } \\
58^{\circ} \text { y } 59^{\circ} \text { de Long. Oeste) }\end{array}$ & 08/09/1986 \\
\hline Landsat - TM & $\begin{array}{l}\text { Porción Sur (entre los } 29^{\circ} \text { y los } 31^{\circ} \text { de Lat. Sur y los } \\
56^{\circ} \text { y } 58^{\circ} \text { de Long. Oeste) }\end{array}$ & $15 / 05 / 1987$ \\
\hline
\end{tabular}

Estas imágenes fueron captadas por el sensor TM (Tematic Mapper), un sensor pasivo que forma parte de los últimos satélites Landsat enviados a orbitar la Tierra. Este sensor es un equipo de barrido multiespectral que posee una resolución espacial de $30 \mathrm{~m}$ y una resolución espectral de 7 bandas, además de contar con una resolución radiométrica de 8 bits. Tanto la resolución espacial como espectral es lo que permite que este sensor ofrezca una mayor precisión para la cartografía temática. Estas imágenes constituyen la principal fuente de información. Una vez que contamos con este insumo se opta por el modo de tratamiento de las mismas y su posterior análisis.

Para llevar adelante el tratamiento y análisis digital, es necesario emplear un procesador digital de imágenes, acompañado por algunas aplicaciones incorporadas en Sistemas de Información Geográfica. Estos procesadores nos permiten realizar las operaciones fundamentales en el tratamiento y análisis cuya meta final, en este caso, es la determinación de la dinámica del uso de suelo urbano. 


\section{5.- TRATAMIENTO DE IMÁGENES}

\section{a. Corrección y mejora de la visualización}

Previamente al tratamiento y determinación del suelo urbano, las imágenes debieron ser procesadas mediante las técnicas de realce encaminadas a mejorar su calidad.

En primer lugar se realizó una composición de las imágenes de manera tal que se obtenga un resultado en el que se integren todas las bandas (1, 2, 3, 4, 5 y 7). En segundo lugar se realizó la Corrección Geométrica de las imágenes, proceso que tiende a eliminar cualquier anomalía detectada en las mismas, en este caso respecto a su localización. Este tipo de corrección incluye cualquier cambio en la posición que ocupan los píxeles que conforman la imagen. Otra operación que se realiza, también a fin de ajustar imágenes con archivos vectoriales, es la corrección a través de puntos de control, utilizando el programa Arc Gis. Este procedimiento parte de una cartografía básica o de otra imagen corregida a la que se pretende ajustar la imagen original. En ese caso, la corrección se realiza mediante localización de los puntos entre la imagen a ser corregida y el documento de referencia.

Luego se llevó a cabo la tarea denominada mejora de imágenes, que consiste en la elección de ciertas composiciones o combinaciones de bandas, que permiten destacar en la imagen algunos fenómenos sobre otros presentes en ellas. En este caso se opta por una composición que incluya a la banda 4 ubicada en el canal rojo, la banda 3 en el canal verde y la banda 2 en el canal azul; o también la composición que contenga a la banda 4 en el canal rojo, la 5 en el verde y la 3 en el azul. De este modo se hacen más visibles las áreas urbanas, objeto de este estudio.

Después se realizó el recorte de Imágenes, destinado a aislar porciones de una imagen que son de nuestro interés para luego poder ensamblarlas y obtener el área que necesitamos, y el mosaico o ensamble de las imágenes, una operación que se realiza a fin de obtener una imagen que contenga de manera integrada las porciones de las imágenes antes seleccionadas que corresponden a distintas partes del departamento.

Finalmente se lleva a cabo el recorte del departamento, en este ultimo paso se procede al recorte de la imagen ensamblada con anterioridad, utilizando como modelo o "molde" un archivo vectorial del departamento Mercedes.

Como resultado de estas operaciones de tratamiento se obtuvieron las siguientes imágenes, la primera corresponde a 1985/1986/1987 y la segunda a 2008 (figuras 2 y 3 respectivamente) 

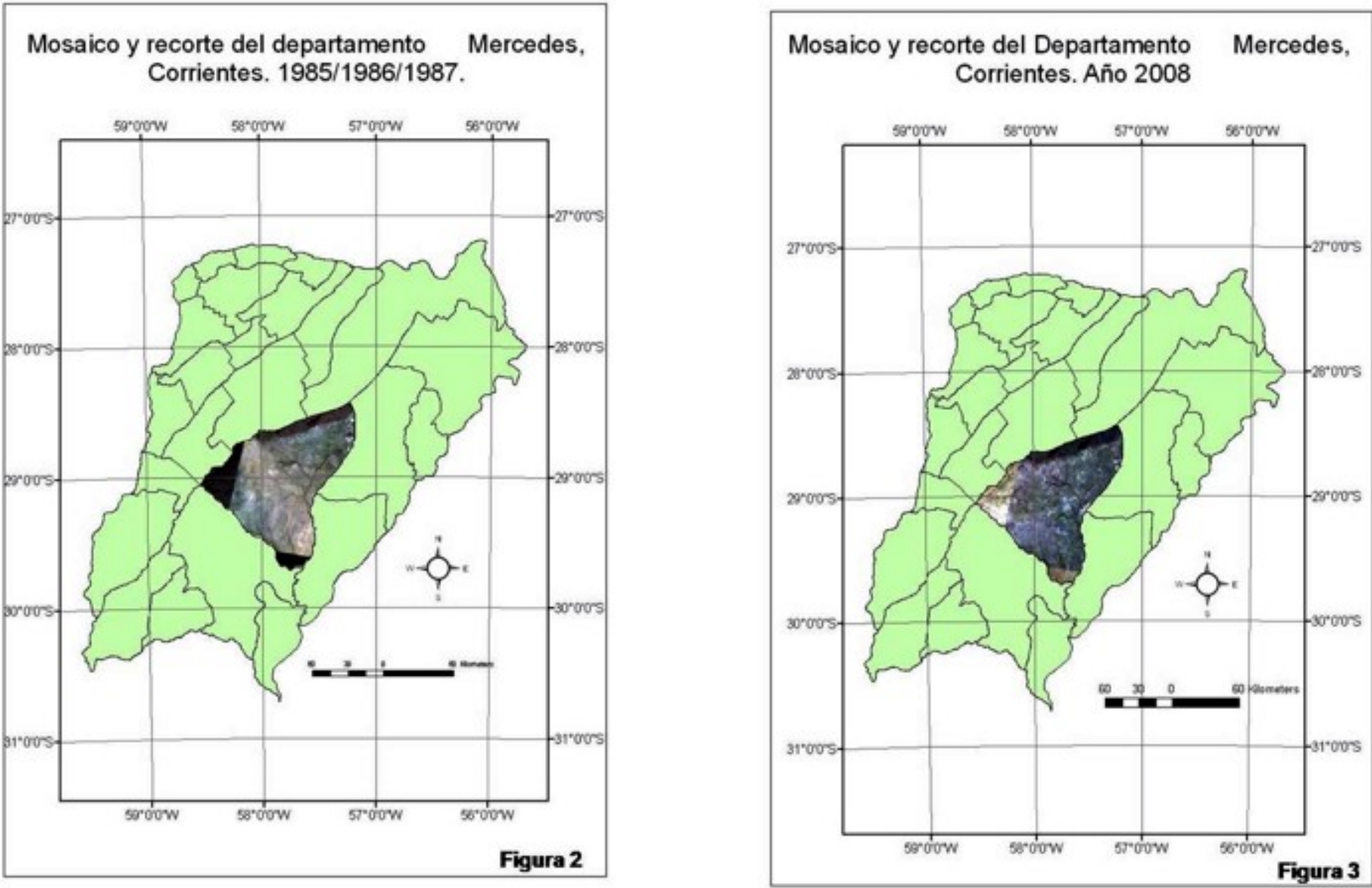

\section{b. Selección de las áreas urbanas a estudiar}

En esta fase del trabajo el objetivo es delimitar las áreas urbanas objeto de nuestro estudio. Este procedimiento puede realizarse tanto con procesadores digitales de imágenes como con sistemas de información geográfica. La selección de las áreas urbanas de interés se realiza sobre la imagen recortada, se delimita el ejido urbano de las tres localidades a través del trazado de un polígono que aísla al mismo del resto del territorio $\mathrm{y}$, de este modo, se pueden definir sus propiedades, por ejemplo la extensión o superficie. Esta operación, o digitalización, se realiza sobre la imagen con el SIG ArcGis, creando previamente en Arc Catalog un nuevo tema.

\section{c. Análisis de imágenes:}

El análisis de las áreas urbanas que corresponden a las localidades se refiere a la extensión de las mismas, por lo tanto se considera un período de tiempo comprendido entre 1985 a 2008 a fin de establecer comparaciones y observar si hubo crecimiento o no y la magnitud del mismo. Las imágenes analizadas contienen las tres diferentes localidades en dos fechas distintas:

a. Mercedes (17 de Noviembre de 1985 - 6 de Abril de 2008)

b. Mariano I. Loza (17 de Noviembre de 1985 - 6 de Abril de 2008)

c. Felipe Yofre (8 de Septiembre de 1986 - 24 de Enero de 2008)

Como resultado del tratamiento digital de las imágenes se obtuvieron las imágenes 4 y 5 , allí se aprecia eldepartamento de Mercedes en su totalidad y las áreas urbanas que corresponden a las tres localidades en ambos períodos de estudio. 

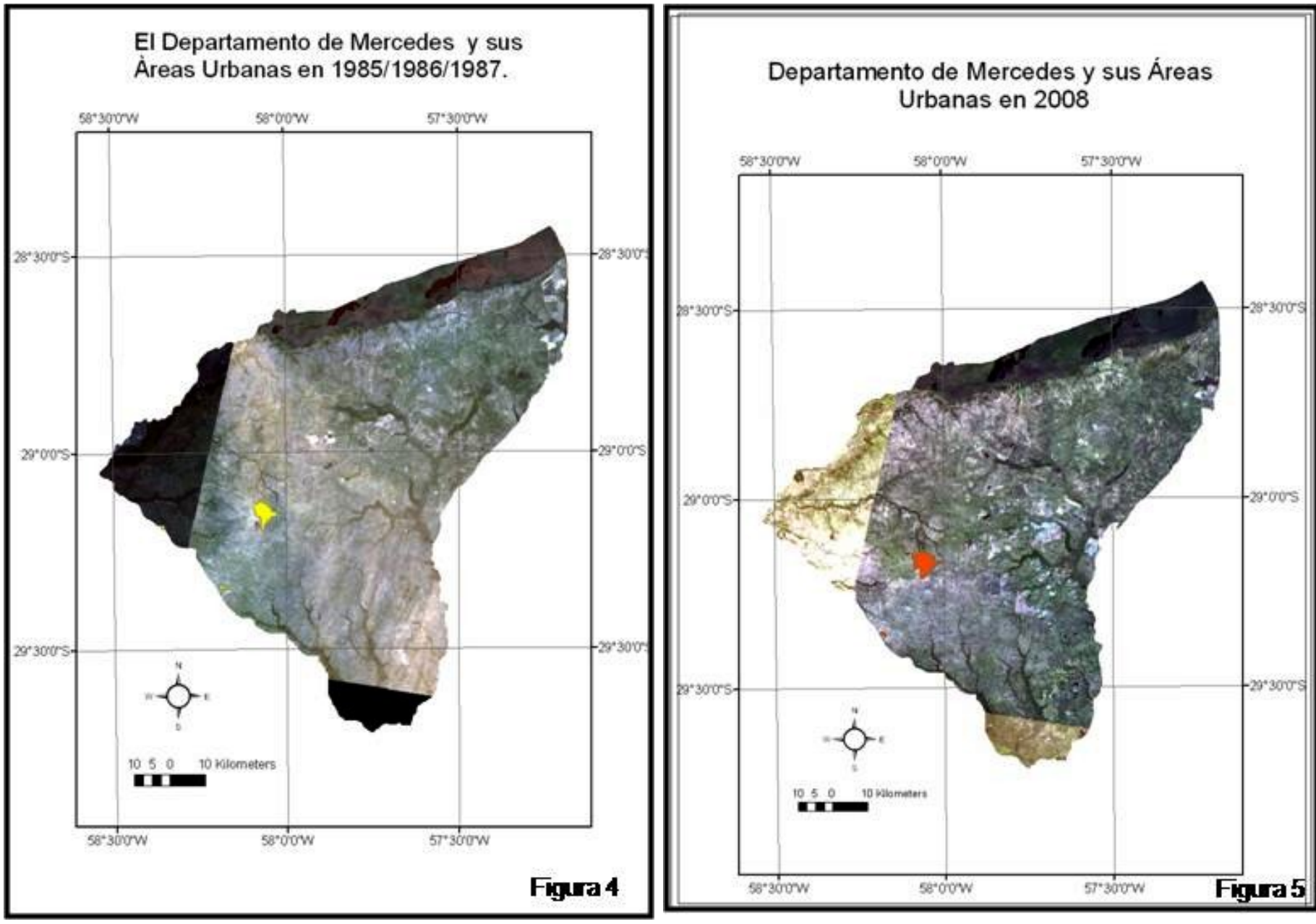

Observando las imágenes podemos señalar que en ambos períodos analizados la ciudad de Mercedes cubrió la mayor extensión urbana, ocupando una superficie de $26,35 \mathrm{Km}^{2}$, en la primera etapa mientras que en 2008 registró una extensión 33,76 $\mathrm{Km}^{2}$. Este incremento de la mancha urbana representó un valor relativo de 28,12\%.

En cuanto a las localidades de Felipe Yofre y Mariano Indalecio Loza se puede decir que ambas son pequeñas localidades que, como ya comentamos, alcanzan a superar los 2000 habitantes en la actualidad. En el primer período Felipe Yofre no alcanza el $\mathrm{Km}^{2}$ de extensión ya que sólo registró $0,9 \mathrm{Km}^{2}$, no obstante en 2008 muestra un total de $1,19 \mathrm{~km}^{2}$ de extensión, apreciándose en este asentamiento el máximo incremento de la mancha urbana, que, en términos relativos, significó un 32,22\%. Finalmente Mariano Indalecio Loza registró una extensión de espacio urbano de $1,57 \mathrm{Km}^{2}$ en la primera fase considerada y en 2008 registró una superficie de $1,94 \mathrm{~km}^{2}$, aumentando así su espacio en un $23,57 \%$. En el gráfico 1 se muestra la extensión de la mancha urbana en ambos períodos para cada localidad. 


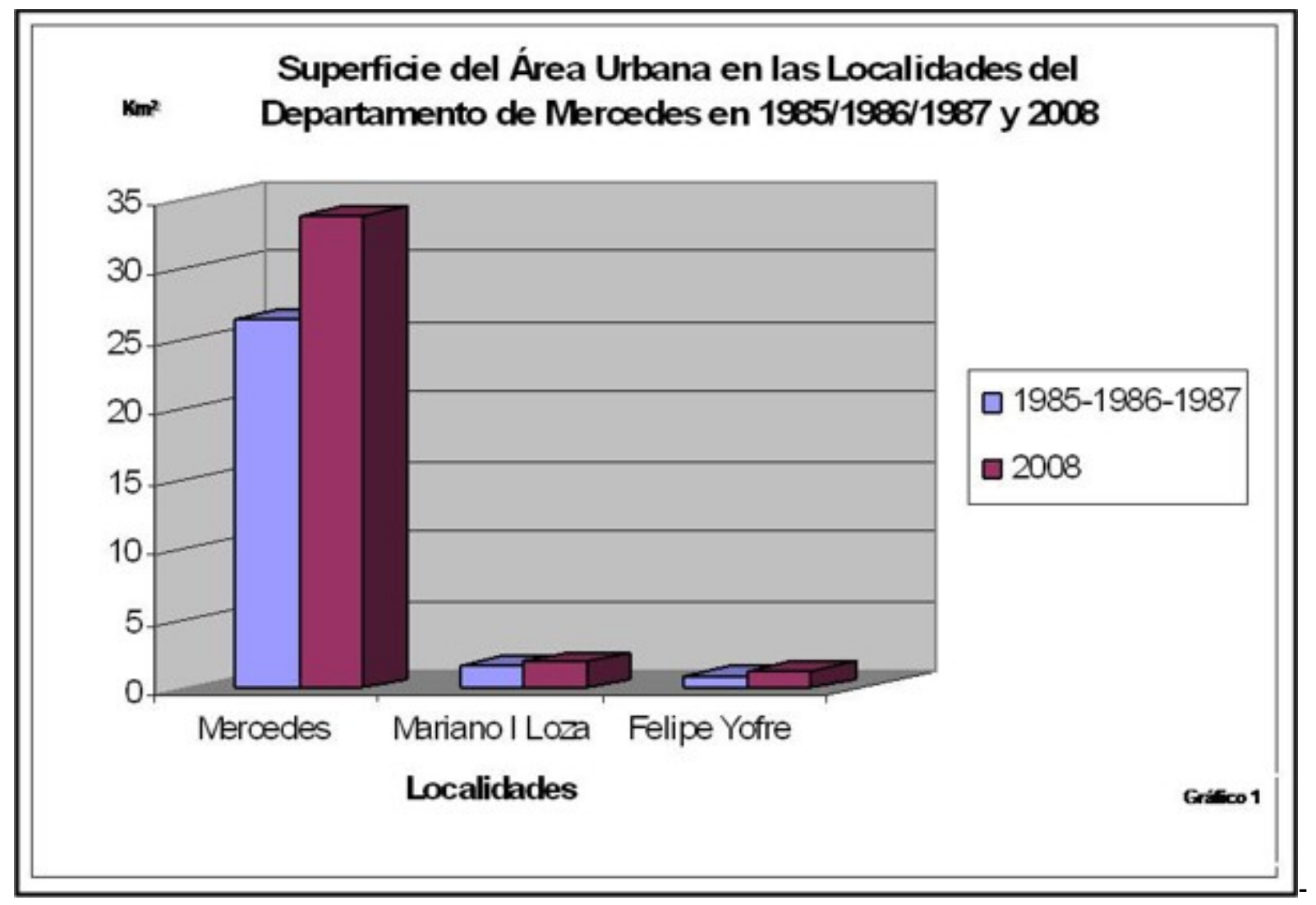

(7) Sitio Web: www.inpe.br

\section{6.- DESCRIPCIÓN DE RESULTADOS:}

Con la utilización de imágenes satelitales disponibles gratuitamente en Internet y con su posterior tratamiento y análisis digital, que consistió en numerosas operaciones que incluyeron la corrección geométrica, las mejoras de imágenes a través de composiciones que permitan una mejor visualización de las áreas urbanas objeto de estudio, el recorte de las áreas del departamento, el ensamble o mosaico de los mismos, la digitalización de las áreas urbanas que dio como resultado una imagen del Departamento de Mercedes sobre el cual se seleccionaron las áreas urbanas tanto en 1985/86/87, como en 2008, hemos podido observar la extensión de las manchas urbanas lo que nos permitió comparar los cambios acontecidos en este período.

Las tres localidades analizadas reúnen el $100 \%$ del uso de suelo urbano del Departamento, Como se observa en el siguiente cuadro, en la actualidad la ciudad de Mercedes es la ciudad que cubre la mayor superficie urbana (95\%) y también la que concentra la mayor población urbana $(91,8 \%)$.

\begin{tabular}{|l|c|c|}
\hline \multicolumn{1}{|c|}{ Localidades } & Porcentaje de Área Urbana & Porcentaje de Población \\
\hline Mercedes & 95 & 91,8 \\
\hline Mariano I Loza & 3,1 & 4,6 \\
\hline Felipe Yofre & 1,9 & 3,6 \\
\hline TOTAL & $\mathbf{1 0 0} \%$ & $\mathbf{1 0 0 \%}$ \\
\hline
\end{tabular}

Si comparamos el crecimiento de la mancha urbana ya señalado anteriormente con el crecimiento de la población en el período estudiado podemos señalar que ambos tienen un ritmo ascendente, no obstante no existe una correspondencia muy estrecha entre amos. Asó podemos apreciar en el gráfico 2 que Mercedes (capital) aumentó su población en un 52,86\%, mientras que la mancha urbana -recordemos- lo hizo en un 28,12\%. Mariano Indalecio Loza, por su parte, creció demográficamente en un $23,62 \%$ mientras que se extendió en más un $23,57 \%$. Finalmente Felipe Yofre fue la de menor crecimiento poblacional, $17,53 \%$, pero la de mayor incremento de la mancha urbana, 32,22\%. 


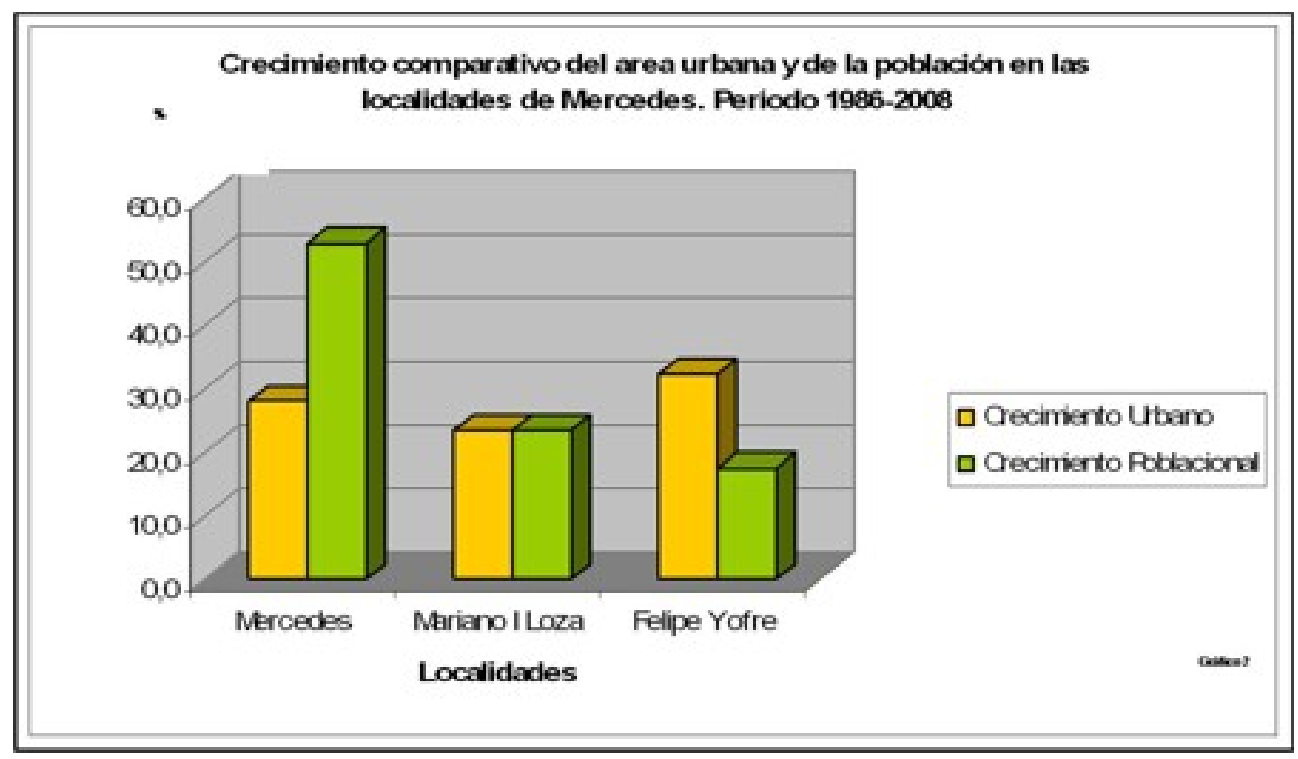

\section{El crecimiento de la ciudad de Mercedes:}

Mercedes, capital del departamento merece un comentario particular, para poder analizarlo hemos incorporado más abajo un esquema que surge de la aproximación a la mancha urbana que cubre esta localidad. Así vemos que el crecimiento en esta urbe se da mayormente hacia el Suroeste y Sureste de la trama urbana con barrios de interés social, aunque en la actualidad ya se evidencia un crecimiento hacia el norte. La expansión urbana encuentra limitantes en los arroyos Las Garzas por el este y Gómez por el oeste, la ciudad se expande o crece ocupando además sitios vacíos o intersticiales.

Esta expansión se debe sobretodo a construcción de viviendas planificadas por parte de INVICO (Instituto de Viviendas de Corrientes). Es así como hacia mediados de la década de 1980 finaliza la construcción de numerosas viviendas de distintas características en el sector oeste de la ciudad, que conforman el barrio José María Gómez, el cual puede se observado en la fotografía C. Este barrio planificado es el más antiguo de la ciudad con respecto a otros de su categoría, es además el mas consolidado.
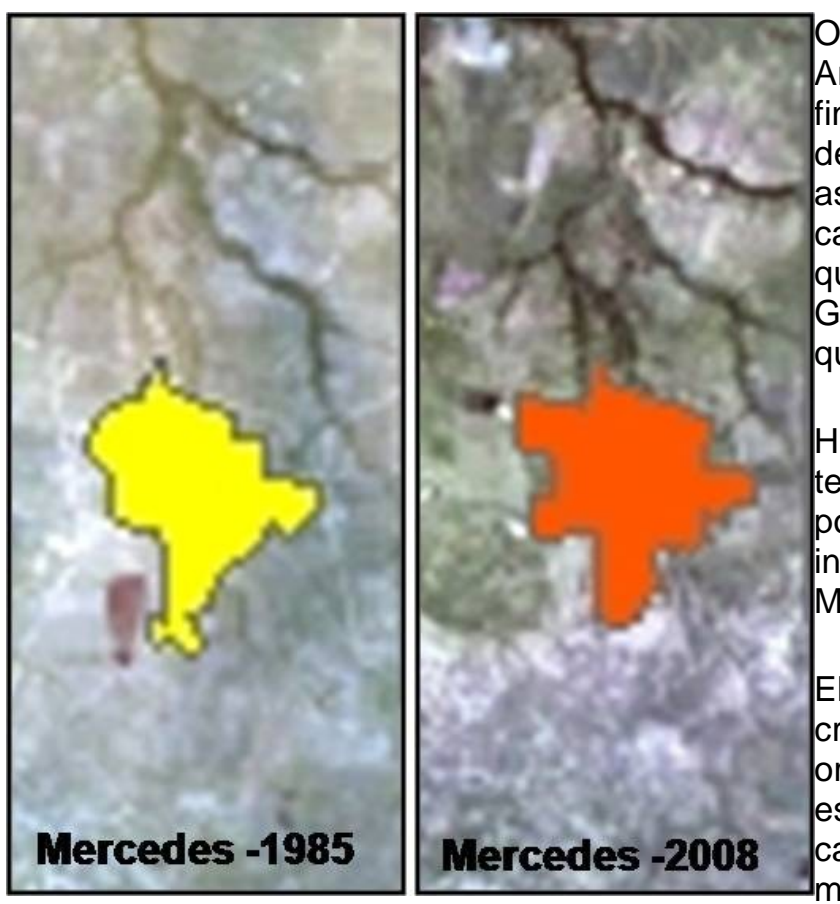

Otro barrio planificado con que cuenta la ciudad de Mercedes es Arturo Illia ubicado en el noroeste, éste comenzó a ser construido a finales de la década de 1980 y es inaugurado a inicios de la década de 1990. La urbanización de la ciudad siguió su evolución ascendente, en forma de viviendas planificadas pero esta vez con características diferentes ya que en algunos terrenos desocupados que quedaban entre las vías del ferrocarril y el barrio José María Gómez fueron construidas viviendas destinadas para las personas que habían sido afectadas por la inundación de 1998-1999.

Hacia comienzos de 2000 nuevos sectores de la ciudad, antes terrenos desocupados de propiedad municipal o privada adquiridos por la provincia, comienzan a agregarse a la ciudad en forma de insipientes urbanizaciones. Así nacen en la parte sureste de Mercedes los Barrios Juan Pablo II, Santa Catalina y Santa Rita.

El crecimiento de la población determina que la ciudad continúe creciendo, la demanda de viviendas crece y, generalmente, son los organismos provinciales, como lo es el INVICO, los que cubren estas necesidades. Esto hace que la ciudad adquiera características particulares en sus edificaciones y que de algún modo el crecimiento urbano sea más ordenado. 


\section{CONSIDERACIONES FINALES:}

La expansión urbana en concordancia con el aumento de población y viceversa han sido uno de los estudios más beneficiados con la disponibilidad de imágenes de satélite de media resolución que han sido captadas por los sensores satelitales desde la década de los setenta. Su alcance gratuito y libre nos permite avanzar en el conocimiento de la expansión urbana de localidades como las que aquí presentamos, dejando evidencia que no existen una correspondencia directa entre el aumento de población y la con expansión o aumento de la mancha urbana ya que ésta siempre se encuentra condicionada por el medio y sus limitantes y, en ocasiones, urbes que no tienen posibilidad de expandirse o propagarse en el territorio consolidan espacios en su interior.

\section{BIBLIOGRAFÍA}

- Bruniard., Enrique D. 1996. Bases Fisiogeográficas para una división regional de la provincia de Corrientes. En Revista Nordeste No 8. Facultad de Humanidades. UNNE.

- Chuvieco, Emilio. 1985. Aportaciones de la Teledetección espacial a la cartografía de ocupación del suelo

- Chuvieco, Emilio. 1996. Fundamentos de Teledetección Espacial. Ediciones Rialp, S.A. Madrid. España.

- García Rodríguez, Pilar; Pérez González María Eugenia. 2005. Degradación de suelos en Castilla La Mancha: Estudio de áreas pilotos mediante teledetección. En: http:www.invenia.es/oai:dialnet.unirioja.es:ART0000111576.

- Geográfica No 13. Revista del Instituto de Geografía. Atlas geográfico de la provincia de Corrientes. Tomo VI: La División regional de la Provincia de Corrientes. 2005. Facultad de Humanidades. UNNE.

- INDEC. Instituto Nacional de Población y Vivienda. Censo Nacional de Población 1980.

- INDEC. Instituto Nacional de Población y Vivienda. Censo Nacional de Población 1991.

- INDEC. Instituto Nacional de Población, Hogares y Vivienda. Censo Nacional de Población 2001.

- Sánchez Negrete, Ángela; Gonzáles, Graciela. 2005. Sitios de valor patrimonial en la ciudad de MercedesCorrientes. Centro de estudios Históricos, Arquitectónicos y Urbanos del Nordeste. Facultad de Arquitectura y Urbanismo de la UNNE. Universidad Nacional del Nordeste. Comunicaciones Científicas y Técnicas 2005. En: http://www.unne.edu.ar/Web/cyt/com2005/7-Tecnologia/T-045.pdf

- Zuleima Molina M., Gladys. 2005. Propuesta metodológica para estudios de dinámica de uso urbano utilizando la teledetección: Maracay, estado Aragua-Venezuela. En Revista Geográfica Venezolana. Universidad de los Andes, Escuela de Ciencias Forestales y Ambientales. En: http://www.invenia.es/oai:dialnet.unirioja.es:ART0000064524. 